\title{
Carbon payments in the Guanzhong-Tianshui region to control land degradation
}

\author{
Zixiang ZHOU ${ }^{1,2}$, Yufeng ZOU $(\bowtie)^{1,2}$ \\ 1 Institute of Water Saving Agriculture in Arid Areas of China, Northwest A\&F University, Yangling 712100, China \\ 2 National Engineering Laboratory for Crop Water Efficient Use, Yangling 712100, China
}

\begin{abstract}
Carbon trading and carbon offset markets are potential policy options for mitigating greenhouse gas emissions and climate change. A price on carbon is expected to generate demand for carbon offsets. In a market-based framework, the carbon price should be high enough to compensate for opportunity costs. We studied a highly-modified agricultural system in the GuanzhongTianshui economic region of China that is typical of many temperate agricultural zones in western China. We quantified the economic returns from agriculture and from carbon plantings (both monoculture and ecological plantings) under five carbon-price scenarios. The mean carbon sequestration is $34 \mathrm{Mg} \cdot \mathrm{hm}^{-2} \cdot \mathrm{a}^{-1}$, and the average annual payment increased to $1146 \mathrm{CNY} \cdot \mathrm{hm}^{-2}$ at a medium carbon price of $50 \mathrm{CNY} \cdot \mathrm{Mg}^{-1} \mathrm{CO}_{2}{ }^{-\mathrm{e}}$. Thus, areas of high priority for conservation and restoration may be restored relatively cheaply in the presence of a carbon market. Overall, however, less carbon is sequestered by ecological plantings (i.e., mixed native trees and shrubs) compared to agriculture.
\end{abstract}

Keywords carbon-price, carbon sequestration, economic returns, Guanzhong-Tianshui economic region, net present value

\section{Introduction}

Carbon sequestration is a key ecosystem service that is dependent on land-use change ${ }^{[1]}$. Carbon trading and the resultant market for carbon offsets are one of the policy options to mitigate greenhouse gas emissions and climate change. Through this market, planting trees presents real opportunities not only for carbon sequestration but also for nature conservation ${ }^{[2]}$. A highly anticipated carbonpayment mechanism termed REDD (reduced emissions from deforestation and degradation) is increasing

Received December 10, 2016; accepted March 6, 2017

Correspondence: zouyufeng1222@163.com incentives to protect threatened forests ${ }^{[3]}$. Economic incentives are required to motivate landowners to invest in ecological reserves (mixed trees and shrubs) ${ }^{[4]}$. In a market-based framework, the carbon price should be high enough to compensate for opportunity costs.

A large amount carbon is released when forests and grasslands are cleared, burned and converted to agricultural systems ${ }^{[5]}$. The carbon supply from agricultural land depends on the relative prices for crops and carbon, as well as assumptions around discount rates, growth rates and $\operatorname{costs}^{[6,7]}$. Richards and Stokes ${ }^{[8]}$ found $250-500 \mathrm{Mt} C$ per year could possibly be sequestered in the US if the $\mathrm{C}$ price was in the range of $10-150 \mathrm{USD} \cdot \mathrm{t}^{-1}$, and upwards of 2000 Mt C per year globally for several decades. van Kooten $^{[9]}$ investigated the costs of sequestering carbon through tree planting and agroforestry and found them to be double the cost of forest conservation. Several recent research reports have assessed, at national or regional scales, the economic potential for new forests to be established under a carbon market at global, regional and local scales ${ }^{[2,4,10-21]}$. These studies assumed the cost of carbon sequestration using different carbon modeling schemes and concluded that the receipt of realistic carbon-related payments can have substantial impacts on future land-use patterns and terrestrial carbon sequestration.

China's central government has formulated a long-term forestry program called Classification-Based Forest Management (CFM). The overall concept of CFM is to apply different management strategies to different categories of forestlands, namely, Commodity Forest $(\mathrm{CoF})$ and Noncommodity or Ecological Welfare Forest (EWF) lands. The CFM program reflects a long-term policy and its implementation covers the entire country. Starting in 2000, China's central government accelerated the reform of $\mathrm{CFM}^{[22]}$. The principal role of China's government is to provide forest managers with subsidies to assure the protection of National EWF lands from logging and to use market mechanisms to promote the productivity of $\mathrm{CoF}$ lands ${ }^{[22]}$. Over the past several decades, China's environment has been degraded and has severely deteriorated due 
to increasing population pressure and escalating economic growth $^{[23]}$. Although there is a greening of the landscape in China due to the governmental policies and land abandonment ${ }^{[24,25]}$, there is also a process of intensification and acceleration of soil degradation and carbon emission due to soil organic matter degradation ${ }^{[26]}$.

In particular, the Qinling Mountains has mainly natural cover for ecological defense with planted tree cover of $80 \%$, which is hoped will gradually lead to reforestation of the sloping agricultural land and will help reduce excessive soil erosion, conserve water resources and alleviate the desertification process ${ }^{[27,28]}$. China initiated its "Grain for Green" project in 1999 as an ambitious conservation program designed to mitigate and prevent soil erosion. The large-scale implementation of the "Grain for Green" project will in the long run contribute to generation of global carbon sinks and ultimately a reduction in atmospheric $\mathrm{CO}_{2}$. Many Chinese scholars found additional benefits of payments for carbon sequestration in some regions ${ }^{[23,29-34]}$. For example, a linked market can improve social welfare and reduce carbon emission intensity for the nation as well as for the Hubei-Guangdong block compared to a separated market ${ }^{[31]}$. Zhang et al. ${ }^{[35]}$ estimated the temporal and spatial changes of the ecological service values within the entire ecosystem, sub-ecosystems and individual ecosystem services based on land use.

The Guanzhong-Tianshui economic region is an important grain-producing area of western China. While reforestation of agricultural land in this region has contributed to improved environmental conditions and carbon sequestration, farm incomes have not benefited significantly ${ }^{[36,37]}$. To compensate for this, the Shaanxi Provincial Government has provided a cash and food subsidy to farmers for 5-8 years to encourage reforestation. However, after the subsidy period terminates, farmers will be challenged to maintain their income from reforested lands. To assess the magnitude of these challenges, it is very important to understand the impact of reforestation on the local economy.

Because plants remove carbon dioxide from the air through photosynthesis as they grow, carbon planting can be used as a geoengineering technique to help sequester carbon emissions. In this paper, we modeled the spatial distribution of monoculture and ecological carbon plantings in the agricultural areas of western China. We quantified the economic returns from these carbon plantings under five carbon markets, i.e., carbon-price scenarios. Finally, we quantified the cost of payments required to locate ecological carbon plantings in areas of high conservation and restoration priority.

\section{Materials and methods}

The Guanzhong-Tianshui economic region is divided into the Guanzhong area, the Shangluo (southern Shanxi) region and Tianshui in Gansu (Fig. 1). The region has a total area of approximately $8.01 \times 10^{4} \mathrm{~km}^{2}$. By the end of 2008 , the total regional population was around 2.9 million with an average population density of 357.39 people per kilometer, making it one of the most underpopulated areas in western China. The Guanzhong-Tianshui economic region is situated in the interior of the country and receives relatively little precipitation of about $530 \mathrm{~mm} \cdot \mathrm{a}^{-1}$, with distinct wet and dry seasons and a warm temperate climate. The topography of the land is smooth with fertile soil (the soil type is a stratified old manured loessial soil or lou soil) with a good distribution of water (the Wei River is the largest tributary of Yellow River), making it well-suited for agriculture and human habitation. Maintaining and promoting the economic and scientific development of the Guanzhong-Tianshui economic region is a major goal of China's Great Western Development Strategy as a way of driving the long-term development of Gansu and Shaanxi, and western China in general. The ecological carbon plantings are constrained to a rainfall zone of $\geqslant 550 \mathrm{~mm} \cdot \mathrm{a}^{-1}$, accounting for $56.2 \%$ of the total area; monoculture carbon plantings, on the other hand, are constrained to a rainfall zone of $350-549 \mathrm{~mm} \cdot \mathrm{a}^{-1}$, accounting for $43.8 \%$ (Fig. 1).

Carbon sequestration in each plantation type was estimated from the carbon sink efficiency of the vegetation type and the NPP (Net primary productivity) was calculated by using the CASA (Carnegie-Ames-Stanford Approach) model ${ }^{[38]}$. The mixed environmental plantings were converted to units of $\mathrm{CO}_{2}{ }_{j}^{-\mathrm{e}}$ using the following equation $^{[39]}$ :

$$
\mathrm{CO}_{2 j}^{-e}=3.667 \times \mathrm{NPP}_{j} / 2
$$

$\mathrm{NPP}_{j}$ values were divided by 2 to convert to carbon and the carbon weights were multiplied by 3.667 to convert to $\mathrm{CO}_{2}{ }_{j}^{-\mathrm{e}}$.

$$
\operatorname{NPP}(x, t)=\operatorname{APAR}(x, t) \times \varepsilon(x, t)
$$

where $t$ represents time and $x$ represents a spatial location (the pixel number), so $\operatorname{APAR}(x, t)$ therefore represents the photosynthetically active radiation (PAR) absorbed by pixel $x$ in month $t\left(\mathrm{MJ} \cdot \mathrm{m}^{-2}\right.$ per month). In this equation, $\varepsilon(x, t)$ represents the actual light utilization efficiency of pixel $x$ in month $t\left(\mathrm{~g} \cdot \mathrm{MJ}^{-1}\right)$.

$$
\begin{gathered}
\operatorname{APAR}(x, t)=\operatorname{SOL}(x, t) \times \operatorname{FPAR}(x, t) \times 0.5 \\
\operatorname{FPAR}(x, t)=\left(\operatorname{FPAR}(x, t)_{\mathrm{NDVI}}+\operatorname{FPAR}(x, t)_{\mathrm{SR}}\right) / 2 \\
\operatorname{FPAR}(x, t)_{\mathrm{NDVI}} \\
=\frac{\left(\mathrm{NDVI}(x, t)-\mathrm{NDVI}_{(i, \text { min })}\right) \times\left(\mathrm{FPAR}_{\text {max }}-\mathrm{FPAR}_{\text {min }}\right)}{\mathrm{NDVI}_{(i, \text { max })}-\mathrm{NDVI}_{(i, \text { min })}} \\
+\mathrm{FPAR}_{\text {min }}
\end{gathered}
$$




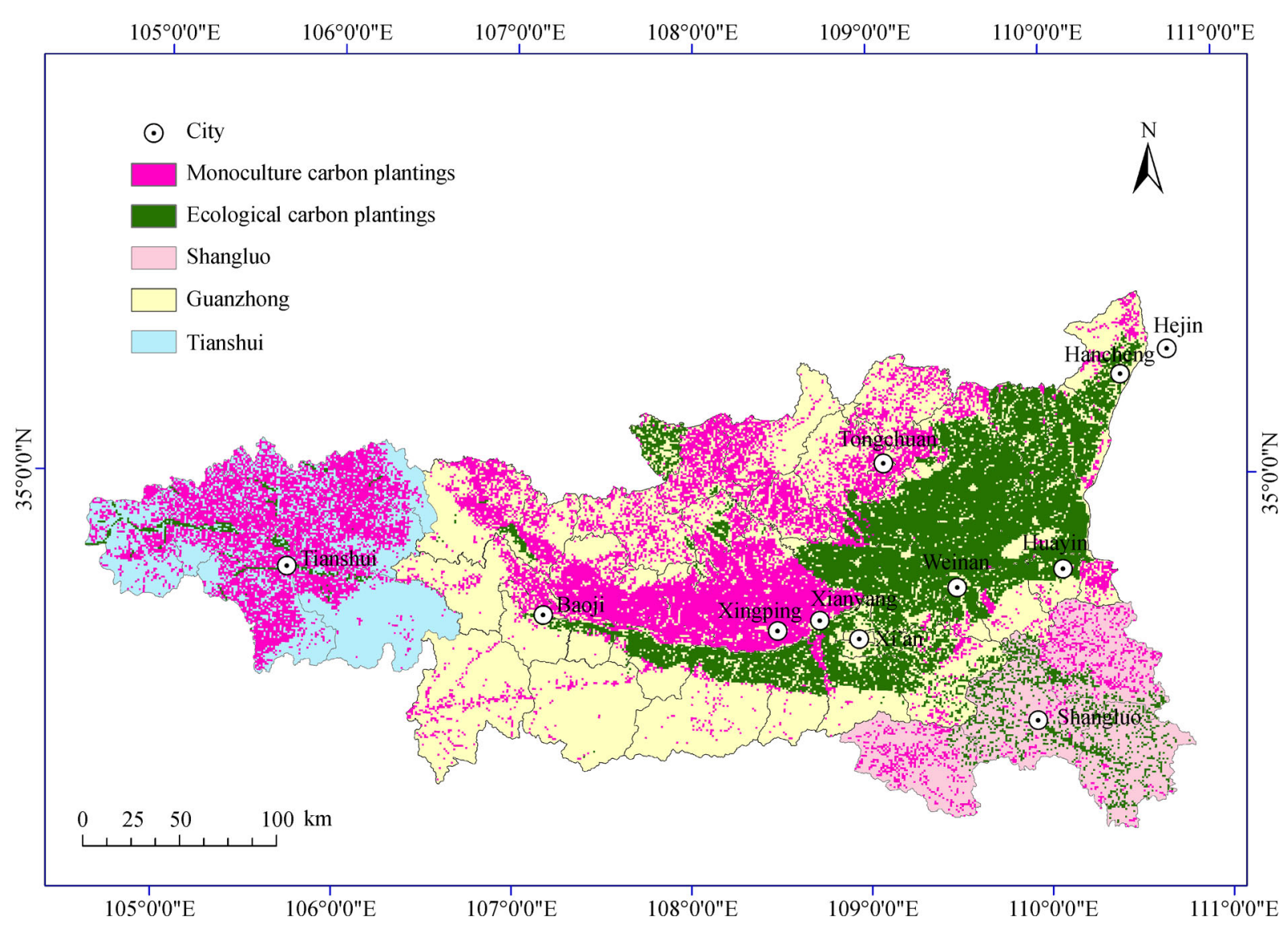

Fig. 1 Location and agricultural ecosystem in Guanzhong-Tianshui economic region

$\operatorname{FPAR}(x, t)_{\mathrm{SR}}$

$=\frac{\left(\mathrm{SR}(x, t)-\mathrm{SR}_{(i, \min )}\right) \times\left(\mathrm{FPAR}_{\text {max }}-\mathrm{FPAR}_{\min }\right)}{\mathrm{SR}_{(i, \max )}-\mathrm{SR}_{(i, \min )}}$

+ FPAR $_{\text {min }}$

$$
\begin{gathered}
\operatorname{SR}(x, t)=\frac{[1-\mathrm{NDVI}(x, t)]}{[1+\mathrm{NDVI}(x, t)]} \\
\varepsilon(x, t)=f_{1}(x, t) \times f_{2}(x, t) \times w(x, t) \times \varepsilon_{\max } \\
f_{1}(x, t)=0.8+0.02 \times T_{\text {opt }}(x)-0.05 \times\left[T_{\text {opt }}(x)\right]^{2} \\
f_{2}(x, t)=\frac{1.184 \times\left\{1+\exp \left[0.3 \times\left(-T_{\text {opt }}(x)-10-T(x, t)\right)\right]\right\}}{1+\exp \left[0.2 \times\left(T_{\text {opt }}(x)-10+T(x, t)\right)\right]}
\end{gathered}
$$

$$
w(x, t)=0.5+0.5 \times E(x, t) / E P(x, t)
$$

where SOL is the total solar radiation $\left(\mathrm{MJ} \cdot \mathrm{m}^{-2}\right)$ at pixel cell $x$ in month $t$, FPAR is the fraction of the incoming
PAR intercepted by green vegetation, the factor 0.5 accounts for the proportion of total solar radiation available for vegetation $(0.4-0.7 \mu \mathrm{m}), \operatorname{FPAR}(x, t)_{\mathrm{NDVI}}$ and $\operatorname{FPAR}(x, t)_{\mathrm{SR}}$ are the fraction of the incoming PAR intercepted by green vegetation calculated by NDVI and SR. FPAR max $_{\text {and }}$ aPAR ${ }_{\text {min }}$ are 0.95 and 0.005 , respectively. $\operatorname{NDVI}_{(i, \text { max })}$ and $\mathrm{NDVI}_{(i, \mathrm{~min})}$ respectively represent $i$ types of vegetation in the maximum and minimum values of the NDVI. SR $(i, \max )$ and $\mathrm{SR}_{(i, \min )}$ represent I vegetation type ratio vegetation index maximum and minimum values, respectively. $\operatorname{NDVI}(x, t)$ and $\operatorname{SR}(x, t)$ respectively represent normalized difference vegetation index and ratio vegetation index at pixel $x$ in $t$ months. $f_{1}(x, t)$ and $f_{2}(x, t)$ indicate the influence of low and high temperature on light use efficiency, $w(x, t)$ is the water stress coefficient which reflects effects of water stress on LUE and $\varepsilon_{\max }$ is the maximum LUE in ideal conditions. $T_{\text {opt }}(x)$ is the mean temperature which reaches a maximum of a regional one year NDVI during the month, $T_{\mathrm{opt}}(x, t)$ is the $t$ month average temperature and $\operatorname{EP}(x, t)$ is the regional potential evapotranspiration (mm per month).

Net present value (NPV) is the present value of a time series of cash flows and is the standard approach for appraising long-term projects. The NPV of permanent carbon reforestation plantings to a time horizon of 2050 
was calculated across the study area as follows:

$$
\mathrm{NPV}=\sum_{t=0}^{T} \frac{p_{i} q_{t j}}{(1+r)^{2}}-\left(\mathrm{EC}_{j}+\sum_{t=0}^{T} \frac{\mathrm{MC}+\mathrm{PFE}_{S}}{(1+r)^{t}}\right)
$$

where $p_{i}$ is carbon prices for $i=30,40,50,80$ and $100 \mathrm{CNY}$ per ton $\mathrm{CO}_{2}{ }_{j}^{-\mathrm{e}}$. These carbon prices were selected to reflect a range of prices realistically expected in a cap and trade carbon market ${ }^{[40]}$. The annual carbon sequestration potential $\left(q_{t j}\right)$, or carbon flux, was taken from the $\mathrm{CO}_{2}{ }^{-\mathrm{e}}{ }_{j}$ values for the tow tree systems $j . r$ is the annual discount rate of $7 \%{ }^{[40,38]}$ and $t$ is the time horizon of 40 years. PFE is profit from agriculture, i.e., the opportunity cost of carbon reforestation plantings; $\mathrm{EC}_{j}$ is establishment cost and $\mathrm{MC}$ is the annual maintenance and transaction cost. Both $\mathrm{EC}_{j}$ and $\mathrm{MC}$ are uniform over the study area ${ }^{[4]}$.

\section{Results}

Much of the study area was profitable for agriculture under long-term average climate and recent commodity prices (Fig. 2). The mean carbon sequestration was $34 \mathrm{Mg} \cdot \mathrm{hm}^{-2} \cdot \mathrm{a}^{-1} \quad \mathrm{CO}_{2}{ }^{-\mathrm{e}}$, with a maximum of $71 \mathrm{Mg} \cdot \mathrm{hm}^{-2} \cdot \mathrm{a}^{-1} \mathrm{CO}_{2}{ }^{-\mathrm{e}}$ and minimum of $5.5 \mathrm{Mg} \cdot \mathrm{hm}^{-2} \cdot \mathrm{a}^{-1}$ $\mathrm{CO}_{2}^{-\mathrm{e}}$. The flat areas are $30-50 \mathrm{Mg} \cdot \mathrm{hm}^{-2} \cdot \mathrm{a}^{-1} \mathrm{CO}_{2}^{-\mathrm{e}}$, and some locations of Qinba Mountains are up to $50 \mathrm{Mg} \cdot \mathrm{hm}^{-2} \cdot \mathrm{a}^{-1} \mathrm{CO}_{2}^{-\mathrm{e}}$ (Fig. 2). Other locations in the north and west of Guanzhong-Tianshui economic region reduced to $30 \mathrm{Mg} \cdot \mathrm{hm}^{-2} \cdot \mathrm{a}^{-1} \mathrm{CO}_{2}{ }^{-\mathrm{e}}$, especially around $\mathrm{Xi}$ 'an. A small number of areas were not profitable for agriculture given their long-term average climate.

Monoculture carbon plantings (Fig. 3) sequestered an average of $34 \mathrm{Mg} \cdot \mathrm{hm}^{-2} \cdot \mathrm{a}^{-1} \mathrm{CO}_{2}^{-\mathrm{e}}$ more than the ecological carbon plantings, which sequestered an average of $33 \mathrm{Mg} \cdot \mathrm{hm}^{-2} \cdot \mathrm{a}^{-1} \mathrm{CO}_{2}{ }^{-\mathrm{e}}$ (Fig. 3) across the entire study area. In locations with rainfall of $\geqslant 550 \mathrm{~mm} \cdot \mathrm{a}^{-1}$ monoculture carbon plantings sequestered an average of $43 \mathrm{Mg} \cdot \mathrm{hm}^{-2} \cdot \mathrm{a}^{-1} \mathrm{CO}_{2}^{-\mathrm{e}}$. Up to $43 \mathrm{Mg} \cdot \mathrm{hm}^{-2} \cdot \mathrm{a}^{-1} \mathrm{CO}_{2}^{-\mathrm{e}}$ could be sequestered in the wettest locations, which received rainfull of up to $1000 \mathrm{~mm} \cdot \mathrm{a}^{-1}$. Monoculture carbon plantings in areas with rainfall of $<350 \mathrm{~mm} \cdot \mathrm{a}^{-1}$ in the north and east of the study area sequestered an average of $30 \mathrm{Mg} \cdot \mathrm{hm}^{-2} \cdot \mathrm{a}^{-1} \mathrm{CO}_{2}{ }^{-\mathrm{e}}$. Ecological carbon plantings sequestered an average of 33 and $27 \mathrm{Mg} \cdot \mathrm{hm}^{-2} \cdot \mathrm{a}^{-1} \mathrm{CO}_{2}{ }^{-\mathrm{e}}$ in the same high and low rainfall areas, respectively. These results suggest that carbon is sequestered more quickly in the humid areas.

Monoculture plantings sequestered more carbon than ecological carbon plantings and they were also more profitable (Fig. 3). For example, in the $50 \mathrm{CNY} \cdot \mathrm{Mg}^{-1}$ $\mathrm{CO}_{2}{ }^{-\mathrm{e}}$ carbon-price scenario, $55 \%$ of the study area was more profitable if monocultures were planted and if existing agricultural uses continued, potentially sequestering $2.8 \mathrm{Gt} \mathrm{CO}_{2}{ }^{-\mathrm{e}}$ by 2050 . The proportion dropped to $45 \%$ for ecological plantings, and $2.1 \mathrm{Gt} \mathrm{CO}_{2}^{-\mathrm{e}}$ was sequestered by 2050 . At $50 \mathrm{CNY} \cdot \mathrm{Mg}^{-1} \mathrm{CO}_{2}^{-\mathrm{e}}$, and where it was profitable to establish carbon plantings, monoculture and ecological carbon plantings were more profitable than existing agriculture by $65 \mathrm{CNY} \cdot \mathrm{hm}^{-2}$ and $55 \mathrm{CNY} \cdot \mathrm{hm}^{-2}$, respectively (Fig. 3).

The profitability of carbon plantings and hence the total area and $\mathrm{CO}_{2}^{-\mathrm{e}}$ sequestered, increased as carbon price increased when it was assumed carbon plantings were established where they would be profitable. In these locations profitability of monoculture plantings and ecological plantings differed (Fig. 4). The figure shows the carbon price versus the estimated annual earnings of

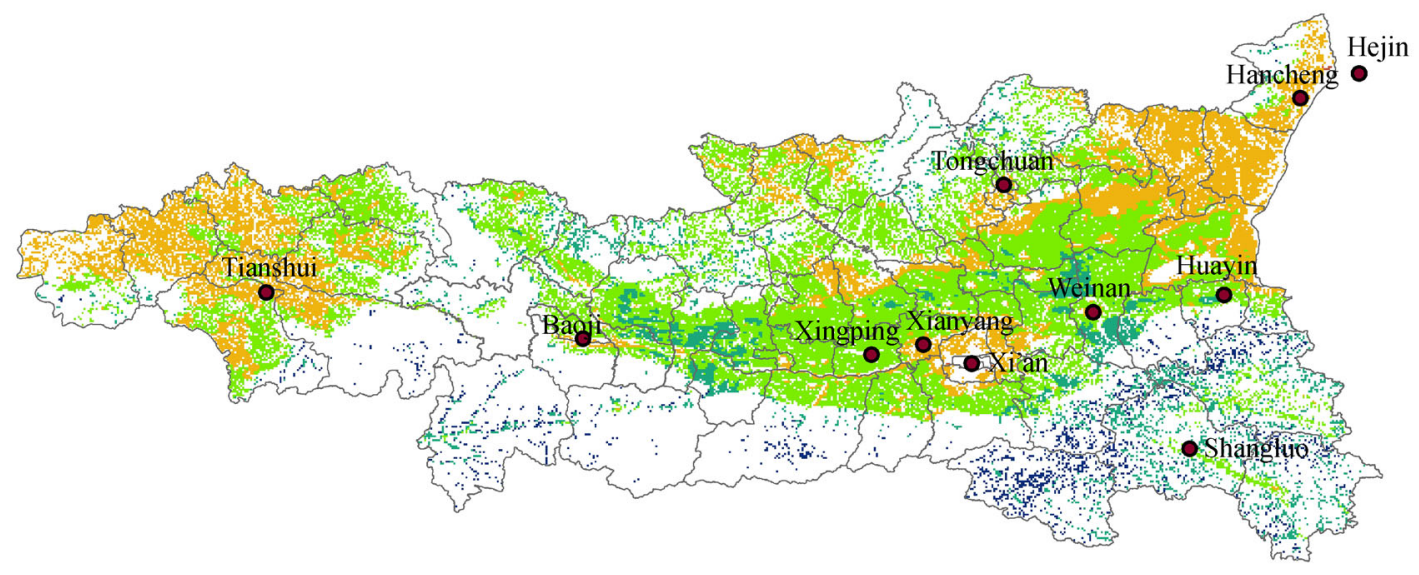

$<10 \square 10-30 \square 30-40 \square 40-50 \square>50 \quad \mathrm{CO}_{2}^{-\mathrm{e}} /\left(\mathrm{Mg} \cdot \mathrm{hm}^{-2} \cdot \mathrm{a}^{-1}\right)$

Fig. 2 Spatial distribution of average simulated annual carbon productivity of agricultural land in Guanzhong-Tianshui economic region 
Monoculture plantings

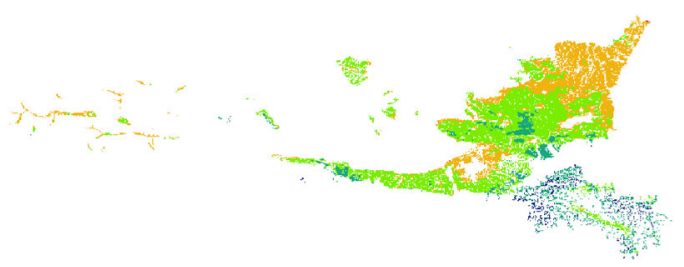

$<10 \square$ - $10-30 \square 30-40$
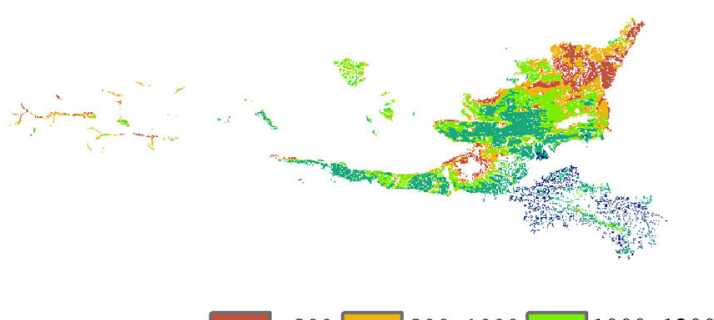

Ecological plantings

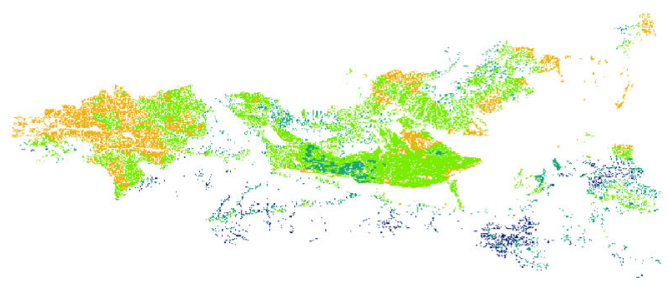

$40-50 \square>50 \quad \mathrm{CO}_{2}^{-\mathrm{e}} /\left(\mathrm{Mg} \cdot \mathrm{hm}^{-2} \cdot \mathrm{a}^{-1}\right)$

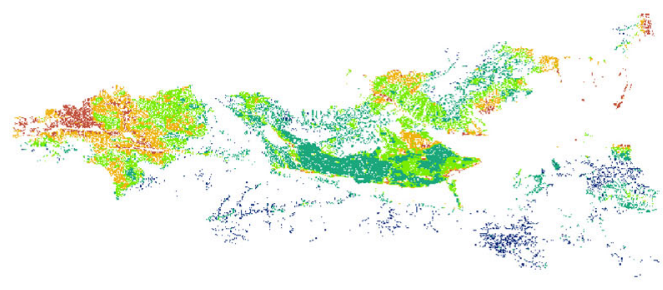

$1200-1600$

$>1600 \mathrm{CNY} \cdot \mathrm{hm}^{-2} \cdot \mathrm{a}^{-1}$

Fig. 3 Spatial distribution of simulated average annual carbon productivity and annual profit from monoculture and ecological plantings according to the land use scenario in Fig. 1

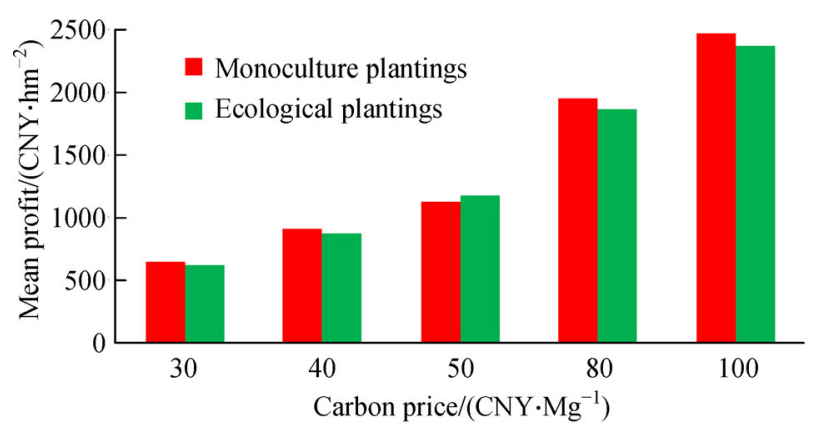

Fig. 4 Mean profit from monoculture and ecological plantings within priority locations for ecological restoration

the carbon trade. The annual earnings of the carbon trade tend to rise from $637-2417 \mathrm{CNY} \cdot \mathrm{hm}^{-2}$ with carbon price increasing by $30-100 \mathrm{CNY} \cdot \mathrm{Mg}^{-1} \mathrm{CO}_{2}^{-\mathrm{e}}$. Furthermore, the carbon price shows a close relationship with the annual earnings of both kinds of plantings, which increase at almost the same rate. Except when the carbon price is $50 \mathrm{CNY} \cdot \mathrm{Mg}^{-1} \mathrm{CO}_{2}^{-\mathrm{e}}$, the annual earnings of monoculture plantings are a little bit higher than ecological plantings. At a low carbon price of $30 \mathrm{CNY} \cdot \mathrm{Mg}^{-1} \mathrm{CO}_{2}^{-\mathrm{e}}$, an average, annual payment of $637 \mathrm{CNY} \cdot \mathrm{hm}^{-2}$ to the landholder would be needed to make ecological plantings competitive with monoculture plantings. The average annual payment increased to $1146 \mathrm{CNY} \cdot \mathrm{hm}^{-2}$ at a medium carbon price of $50 \mathrm{CNY} \cdot \mathrm{Mg}^{-1} \mathrm{CO}_{2}^{-\mathrm{e}}$ and increased to $2417 \mathrm{CNY} \cdot \mathrm{hm}^{-2}$ at a high carbon price of $100 \mathrm{CNY} \cdot \mathrm{Mg}^{-1} \mathrm{CO}_{2}{ }^{-\mathrm{e}}$ (Fig. 4).

In Fig. 5, the spatial distribution of net economic returns in reforested areas is according to the median scenario parameter values (i.e., $r$ is the annual discount rate of 7\%). Different patterns for net economic returns occur at all carbon prices. When the carbon price increases, the net economic returns of the studied areas are higher. Also, the economic returns in the south-eastern region are higher than the north-west, because the rainfall is much greater in the south-east.

\section{Discussion}

The economic viability of agricultural land use in the study area was investigated in this paper. The main finding was that reforestation is currently nonviable according to a standard cost-benefit analysis using the current Kyoto Protocol's Clean Development Mechanism accounting rules and current estimates of the economic values of carbon. Compared with Tengberg et al. ${ }^{[41]}$, the economic benefits of carbon sequestration are too low to fund ecocompensation schemes on their own but can provide supplementary funding. In particular, the future viability of reforestation is uncertain, because of severe uncertainty associated with future carbon accounting rules and the future economic values of carbon.

We calculated the carbon sequestration in China's agricultural land under the present carbon market. 

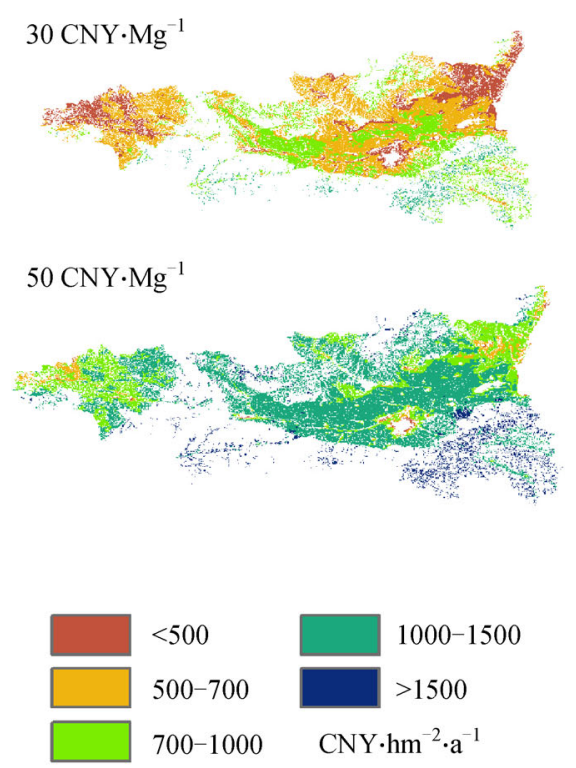
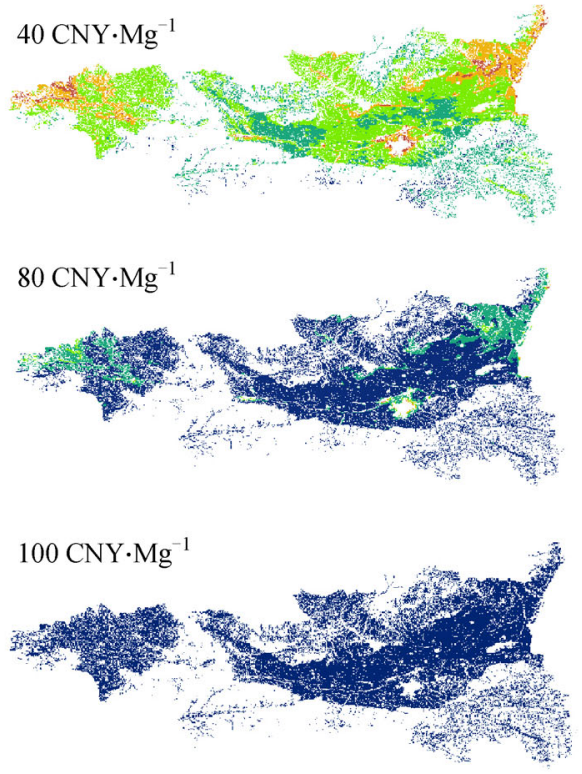

Fig. 5 Spatial distribution of net economic returns to reforestation for a range of carbon prices using scenario parameter values $(r=7 \%)$

Consistent with the result of previous studies ${ }^{[39,42]}$, due to some changes in economic parameters, land carbon sequestration will increase over the period to 2050. Previous studies had concentrated mostly on Shaanxi, none had focused on the Guanzhong-Tianshui economic region, which is an important agricultural production area of western China. The spatial distribution of carbon sequestration was consistent with the results of Song et al. ${ }^{[39]}$, with the south-eastern region higher than the northwest.

China is implementing its National Climate Change Programme, which includes mandatory national targets for reducing energy intensity and the discharge of major pollutants, increasing forest coverage and increasing the share of renewable energy ${ }^{[40]}$. China's government laid down in the Twelfth Five Year Plan (2011-2015) the aim to gradually develop a carbon trading market and adopt a carbon tax. The first pilot scheme in Shenzhen started operation in June 2013. The expectations for the future carbon price levels are best interpreted as an aggregation of best guesses by a subset of people who have knowledge and informed views about the factors that will determine future prices ${ }^{[40]}$. The China Carbon Pricing Survey $2013^{[40]}$ indicated that the average expected prices derived from surveys such as this one differ conceptually from forward prices in markets, which reflect market expectations but adjust them for risk and are subject to demand and supply of capital. They also differ conceptually from forecasts of prices that are based on quantitative analysis of underlying market factors, and assumptions about policy settings. The average expected carbon price is $32 \mathrm{CNY} \cdot \mathrm{Mg}^{-1}$ in 2014, $41 \mathrm{CNY} \cdot \mathrm{Mg}^{-1}$ in 2016 and
$53 \mathrm{CNY} \cdot \mathrm{Mg}^{-1}$ in 2018. However there is significant uncertainty about price levels. The combined average expected carbon price from China's seven pilot emissions trading schemes (ETS) and carbon tax in 2020 is $70 \mathrm{CNY} \cdot \mathrm{Mg}^{-1}\left(8.50 \mathrm{EUR} \cdot \mathrm{Mg}^{-1}, 11.50 \mathrm{USD} \cdot \mathrm{Mg}^{-1}\right)$. The majority of respondents expect the overall price of carbon in China to be lower than the EU ETS until 2020, however by 2025 a majority expects China's carbon price to be similar to or higher than the EU ETS price.

The opportunity cost is taken from values for agricultural land. Some studies ${ }^{[7]}$ have used returns from current land uses as the opportunity cost. Establishing carbon plantings is not simply analogous to switching crops; the land under forests needs to be committed for decades (at least), and hence it is a difficult and costly decision to reverse. It is therefore also unlikely that land committed to carbon plantings will increase in value at the same rate as other agricultural land (except perhaps for some small scale plantations which may add amenity value to a property $)^{[43]}$. For this reason, we consider that land value provides a better measure of the opportunity cost of converting that land to carbon plantings, since it includes the loss of option value as well as the current land use.

International instruments such as The Kyoto Protocol's Clean Development Mechanism, reducing emissions from deforestation, and reducing emissions from deforestation and forest degradation (REDD + ) create incentives that may negatively affect biological diversity and reduce ecosystem complexity ${ }^{[4]}$. The policy of maximizing treebased carbon sequestration may encourage replacement of old-growth forest cover with fast-growing monocultures ${ }^{[4]}$. Through compensating landholders for lost income when 
they maintain old-growth forest, the landholders could avoid some potentially unwanted outcomes. Carbon rights understood as title to carbon credits, have an odd status in the REDD + debate ${ }^{[45,46]}$. They are closely associated with the belief that REDD + will generate economic rents which means framing the discussion in terms of entitlement to revenues beyond mere financial compensations.

There may be other substantial risks associated with widespread carbon plantings, whether monoculture or ecological ${ }^{[4]}$. Increased tree cover in agricultural landscapes increases water interception, reduces runoff and groundwater recharge which then reduces water availability for human consumption ${ }^{[47]}$. Additionally, the widespread replacement of productive agricultural crops with forests can affect food security. The future assessments should quantify these co-benefits and trade-offs when government encourages carbon plantings.

\section{Conclusions}

As the carbon price increases, the profitability of carbon plantings will also increase and the area of carbon plantings will expand, so the amount of carbon sequestered will rise, assuming that carbon plantings are established where they would be profitable. China will proceed to introduce national emissions trading, probably in conjunction with a carbon tax. Carbon price levels are expected to rise, in time exceeding those currently prevailing in the EU emissions trading scheme, and almost all expected further targets to be adopted in 2025 and 2030, possibly in the form of absolute limits on emissions.

Acknowledgements This work was supported by the National Natural Science Foundation of China (41371020), Fundamental Research Funds for the Central Universities (GK201502010), China Postdoctoral Science Foundation on the 58th Group (2015M582706), Postdoctoral Scientific Research Project Foundation of Shaanxi Province in 2015, and China 111 Project (B12007).

Compliance with ethics guidelines Zixiang Zhou and Yufeng Zou declare that they have no conflict of interest or financial conflicts to disclose.

This article does not contain any studies with human or animal subjects performed by any of the authors.

\section{References}

1. Padilla F M, Vidal B, Sánchez J, Pugnaire F I. Land-use changes and carbon sequestration through the twentieth century in a Mediterranean mountain ecosystem: implications for land management. Journal of Environmental Management, 2010, 91(12): 2688-2695

2. Bekessy S A, Wintle B A. Using carbon investment to grow the biodiversity bank. Conservation Biology, 2008, 22(3): 510-513

3. Venter O, Laurance W F, Iwamura T, Wilson K A, Fuller R A, Possingham H P. Harnessing carbon payments to protect biodiversity. Science, 2009, 326(5958): 1368

4. Crossman N D, Bryan B A, Summers D M. Carbon payments and low-cost conservation. Conservation Biology, 2011, 25(4): 835-845

5. Penman J, Gytarsky M, Hiraishi T, Krug T, Kruger D, Pipatti R, Buendia L, Miwa K, Ngara T, Tanabe K, Wagner F. Good practice guidance for land use, land-use change and forestry. Intergovernmental Panel on Climate Change, 2003, 35(5): 103-105

6. Birch J C, Newton A C, Aquino C A, Cantarello E, Echeverría C, Kitzberger T, Schiappacasse I, Garavito N T. Cost-effectiveness of dryland forest restoration evaluated by spatial analysis of ecosystem services. Proceedings of the National Academy of Sciences of the United States of America, 2010, 107(50): 21925-21930

7. Paterson S B, Brett A. Food-carbon trade-offs between agriculture and reforestation land uses under alternate market-based policies. Ecology and Society, 2012, 17(3): 213-226

8. Richards K R, Stokes C. A review of forest carbon sequestration cost studies: a dozen years of research. Climatic Change, 2004, 63 (1): $1-48$

9. van Kooten G C, Eagle A J, Manley J, Smolak T. How costly are carbon offsets? A meta-analysis of carbon forest sinks. Environmental Science \& Policy, 2004, 7(4): 239-251

10. Ahn S. How feasible is carbon sequestration in Korea? A study on the costs of sequestering carbon in forest. Environmental and Resource Economics, 1999, 81(4): 812-824

11. Bolliger J, Hagedorn F, Leifeld J, Böhl J, Zimmermann S, Soliva R, Kienast F. Effects of land-use change on carbon stocks in Switzerland. Ecosystems, 2008, 11(6): 895-907

12. Cacho O J, Lipper L, Moss J. Transaction costs of carbon offset projects: a comparative study. Ecological Economics, 2013, 88: 232-243

13. Dymond J R, Ausseil A G, Ekanayake J C, Kirschbaum M U. Tradeoffs between soil, water, and carbon - a national scale analysis from New Zealand. Journal of Environmental Management, 2012, 95(1): 124-131

14. Jackson R B, Jobbágy E G, Avissar R, Roy S B, Barrett D J, Cook C W, Farley K A, le Maitre D C, McCarl B A, Murray B C. Trading water for carbon with biological carbon sequestration. Science, 2005, 310(5756): 1944-1947

15. Olschewski R, Benítez P C. Secondary forests as temporary carbon sinks? The economic impact of accounting methods on reforestation projects in the tropics. Ecological Economics, 2005, 55(3): 380394

16. Zaehle S, Bondeau A, Carter T R, Cramer W, Erhard M, Prentice I C, Reginster I, Rounsevell M, Sitch S, Smith B, Smith P C, Sykes M. Reginster M D A, Rounsevell S S, Benjamin S, Pascalle S C, Sykes S M. Projected changes in terrestrial carbon storage in Europe under climate and land-use change, 1990-2100. Ecosystems, 2007, 10(3): 380-401

17. de Oliveira S P, de Lacerda N B, Blum S C, Escobar M E O, de Oliveira T S. Organic carbon and nitrogen stocks in soils of Northeastern Brazil converted to irrigated agriculture. Land Degradation \& Development, 2015, 26(1): 9-21

18. Muñoz-Rojas M, Jordán A, Zavala L M, De la Rosa D, AbdElmabod S K, Anaya-Romero M. Impact of land use and land cover changes on organic carbon stocks in Mediterranean soils (19562007). Land Degradation \& Development, 2015, 26(2): 168-179

19. Luis P A, Luisa D J, Beatriz L G. Management effects on soil organic carbon stock in Mediterranean open rangelands - treeless 
grasslands. Land Degradation \& Development, 2014, 26(1): 22-34

20. Brevik E C, Cerdà A, Mataix-Solera J, Pereg L, Quinton J N, Six J, Van Oost K. The inter disciplinary nature of soil. SOIL, 2015, 1(1): $117-129$

21. Leeuwen J P, Lehtinen T, Lair G J, Bloem J, Hemerik L, Ragnarsdóttir K V, Gísladóttir G, Newton J S, de Ruiter P C. An ecosystem approach to assess soil quality in organically and conventionally managed farms in Iceland and Austria. Soil Discussion, 2015, 2015(1): 83-101

22. Dai L, Zhao F, Shao G, Zhou L, Tang L. China's classificationbased forest management: procedures, problems, and prospects. Environmental Management, 2009, 43(6): 1162-1173

23. Xu W, Yin Y, Zhou S. Social and economic impacts of carbon sequestration and land use change on peasant households in rural China: a case study of Liping, Guizhou Province. Journal of Environmental Management, 2007, 85(3): 736-745

24. Miao C Y, Yang L, Chen X H, Gao Y. The vegetation cover dynamics (1982-2006) in different erosion regions of the Yellow River Basin, China. Land Degradation \& Development, 2012, 23 (1): $62-71$

25. Zhao G, Mu X, Wen Z, Wang F, Gao P. Soil erosion, conservation, and eco-environment changes in the loess plateau of China. Land Degradation \& Development, 2013, 24(24): 499-510

26. Li X H, Yang J, Zhao C Y, Wang B. Runoff and sediment from ochard terraces in southeastern China. Land Degradation \& Development, 2014, 25(2): 184-192

27. Leh M, Bajwa S, Chaubey I. Impact of land use change on erosion risk: an integrated remote sensing, geographic information system and modeling methodology. Land Degradation \& Development, 2013, 24(5): 409-421

28. Mandal D, Sharda V N. Appaisal of soil erosion risk in the eastern Himalayan region of India for soil conservation planning. Land Degradation \& Development, 2013, 24(5): 430-437

29. Cao S, Xu C, Chen L, Wang X. Attitudes of farmers in China's northern Shaanxi Province towards the land-use changes required under the Grain for Green Project, and implications for the project's success. Land Use Policy, 2009, 26(4): 1182-1194

30. Chuai X, Huang X, Lai L, Wang W, Peng J, Zhao R. Land use structure optimization based on carbon storage in several regional terrestrial ecosystems across China. Environmental Science \& Policy, 2013, 25(25): 50-61

31. Liu Y, Feng S H, Cai S F, Zhang Y X, Zhou X, Chen Y B, Chen Z M. Carbon emission trading system of China: a linked market vs. separated markets. Frontiers of Earth Science, 2013, 7(4): 465-479

32. Yin R, Zhao M. Ecological restoration programs and payments for ecosystem services as integrated biophysical and socioeconomic processes-China's experience as an example. Ecological Economics, 2012, 73: 56-65

33. Zhong T Y, Huang X J, Zhang X Y, Wang K. Temporal and spatial variability of agricultural land loss in relation to policy and accessibility in a low hilly region of southeast China. Land Use
Policy, 2011, 28(4): 762-769

34. Zhou D, Zhao S, Zhu C. The Grain for Green Project induced land cover change in the Loess Plateau: a case study with Ansai County, Shanxi Province, China. Ecological Indicators, 2012, 23(4): 88-94

35. Zhang J J, Fu M C, Zeng H, Geng Y H, Hassani F P. Variations in ecosystem science values and local economy in pesponse to land use: a case study of Wu' an, China. Land Degradation \& Development, 2013, 24(3): 236-249

36. Xu Q X, Wang T W, Cai C F, Li Z X, Shi Z H. Effects of soil conservation on soil properties of citrus orchards in the ThreeGorges Area, China. Land Degradation \& Development, 2012, 23 (1): $34-42$

37. Zhou S, Yin Y, Xu W, Ji Z, Caldwell I, Ren J. The costs and benefits of reforestation in Liping County, Guizhou Province, China. Journal of Environmental Management, 2007, 85(3): 722-735

38. Lü Y, Fu B, Feng X, Zeng Y, Liu Y, Chang R, Sun G, Wu B. A policy-driven large scale ecological restoration: quantifying ecosystem services changes in the Loess Plateau of China. PLoS One, 2012, 7(2): e31782

39. Song F Q, Kang M Y, Zheng Z L, Wang L C, Wang G Q, Feng D X. Variations of NPP and carbon stock benefits before and after the Grain for Green Project in Northern Shaanxi. Beijing: Mechanical Engineering and Intelligent Systems, 2012, Part 1: 2195-196, 12371242

40. Jotzo F, Boer D D, Kater H. China carbon pricing survey 2013, China Carbon Forum, 2013

41. Tengberg A, Radstake F, Zhang K, Dunn B. Scaling up of sustainable land management in the Western People's Republic of China: evaluation of a 10-year partnership. Land Degradation \& Development, 2016, 27(2): 134-144

42. Deng L S. Z P. Carbon storage dynamics through forest restoration from 1999 to 2009 in China: a case study in Shaanxi Province. Journal of Food Agriculture and Environment, 2013, 11(2): 13631369

43. Schrobback P, Adamson D, Quiggin J. Turning water into carbon: carbon sequestration and water flow in the Murray-Darling Basin. Environmental and Resource Economics, 2011, 49(1): 23-45

44. Stickler C M, Nepstad D C, Coe M T, McGrath D G, Rodrigues H O, Walker W S, Soares-Filho B S, Davidson E A. The potential ecological costs and cobenefits of REDD: a critical review and case study from the Amazon region. Global Change Biology, 2009, 15 (12): 2803-2824

45. Karsenty A, Vogel A, Castell F. "Carbon rights", REDD plus and payments for environmental services. Environmental Science \& Policy, 2014, 35(6): 20-29

46. Phelps J, Friess D A, Webb E L. Win-win REDD + approaches belie carbon-biodiversity trade-offs. Biological Conservation, 2012, 154(7): 53-60

47. van Dijk A I J M, Renzullo L J. Water resource monitoring systems and the role of satellite observations. Hydrology and Earth System Sciences, 2010, 7(4): 2360-2364 